\title{
Ecophilosophy and Cultural Environment
}

\author{
Irina Ponizovkina \\ Department of History and Philosophy \\ Plekhanov Russian University of Economics (PRUE) \\ Moscow, Russia \\ E-mail: irina-ponizovkin@mail.ru
}

\author{
Elena Agibalova \\ Department of Foreign Languages \\ Plekhanov Russian University of Economics (PRUE) \\ Moscow, Russia \\ E-mail: elenagib@rambler.ru
}

\begin{abstract}
The article is dedicated to the development of ecophilosophic view on the modern world. The authors focus on the theoretical and practical importance and relevance of this problem andsuggest expanding the framework of philosophic sense attributed to the notions of ecology and environment. The article pays particular attention to the importance of natural and cultural heritage sites in finding solutions to the problems of social ecologic safety and for ecophilosophic modeling of the future.
\end{abstract}

Keywords-ecology; social ecology; ecophilosophy; environmental culture; cultural environment; environmental awareness

\section{INTRODUCTION}

For several decades, environmentalproblems have been $p$ ersistently reminding about themselves in the form of natural disasters, degradation of natural environment, climate changes, etc. This subject seems to be always in the center of attention: special journals are issued (for example, EkologiyaRossiy, the Global Nest, etc.), dedicated columns in the press are published, environmental organizations are created (the Global Environment Facility, WSPA, the World Wildlife Fund, Greenpeace, etc.), international and governmental environmental programs are launched (monitoring of the environment, GeosphereBiosphere Programme, LOICZ, LUCC, GCTE and other).

But there is a feeling that the depth of the environmental problem has been underestimated and hasn't been studied well enough. The need to deal with these issues not only in breadth (embracing new levels and structures of the territorial administrative authority and general public of different nations) but also in-depth, developing an appropriate ecological worldview and perception, studying and comprehending the internal complexity and ambiguity of the environmental problem emerged long time ago. We speak, primarily, of acategorical problem which only at first glance seems to be a purely theoretical debate about definitions.

The new emerging branch of knowledge - ecological philosophy - is meant to reveal the underlying prerequisites of environmental problems, to expand the range of problems and to show their importance for the future of mankind.

\section{SUBJECT MATTER AND DEFINITIONS}

In the Ecology section we usually find data on air and water pollution, the disappearance of animals and many plant species, the scarcity of natural resources, change in climate and radiation background, etc. This information is relevant and necessary for developing the awareness of today's school and university students, future experts. However, they lie within the familiar traditional bioecology. When looking through educational and scientific literature, one can find such words as "social ecology", "ecology of society", "human ecology", "ecohumanism" more and more often along with the usual concepts of "ecology", "environmental problems".

Thus, over the last decades, the concept of "ecology" acquired a broader, more socially-focused sense in comparison with the term proposed in the 19th century by the German biologist E. Haeckel. This is encouraging as we see the emerging trend towards the deepening of research in the spirit of Yu.M. Lotman, "Culture is the ecology of human society. This is the atmosphere that humanity creates around itself to continue existing in order to survive" [http://imperiya.by/video/yPXXEyFjnSZ/chto-takoe-kulturalotman.html (Access date: 01.06.2018)].

There are two main approaches to ecology: biocentric and anthropocentric (humanitarian). A new technocratic approach is actively developing. Their importance can be viewed in terms of complementarity. Biocentric approach suggests the equivalence of all living things and the primacy of nature over man. Anthropocentric approach focuses on the problems of a man and his relations with the environment as a condition of his existence and development. Technocratic area involves the development and dissemination of various technologies (resource-saving, purification), regulatory and prohibitive documents, etc. Nature and the environment are perceived as objects that are used and protected at the same time. This is not enough to solve environmental problems. It is necessary to take into account the social aspects and psychology of a person, which implies a humanitarian area. It includes the change in the value system, the adjustment of the world outlook, the development of a new ecological culture in the context of universal human culture.

With this approach, the concepts of social ecology, ecology of society, cultural ecology have an additional semantic connotation, and their content includes environmental issues arising within the society, generated by 
the social environment and the cultural and historical environment, problems of the "second nature" created with the hands and mind of a man. After all, the etiology of the word ecology ("oikos", which means house, dwelling and "logos" - science, concept) does not limit its importance to the "nature protection" aspect. The main objective of ecology is to identify the acceptable forms and boundaries of the mutual influence of a man and the environment, so as not to destroy the equilibrium system of vital activity that has been developing over the centuries.

We need to remember at the same time that the environment is not only nature and natural objects. By the beginning of the new millennium, only about $3-5 \%$ of the total area was considered "close to nature", and only $1 \%$ was in a kind of "natural" state. Hence, the rest is cultivated environment. About $70 \%$ of the area in highly industrialized countries are in socio-economic use, and $20-25 \%$ of the total area is used for human settlements and transport communications [1].In developed countries, the majority of the population are urban dwellers. Historically, the emergence of the social space in the form of a city marked the emergence of a new type of relationship not only between man and the "first nature", but also the creation of a specific human habitat - culture. Man himself creates this new reality. A person interacts with this environment daily. It largely determines the quality of the person's life space and it increasingly affects his development, health, well-being and relationships with the world around him.

Sweeping changes that took place over the last centuries brought unprecedented mobility into the human perception of space. Today, the social space for the subject is the world around him, which is never neutral and senseless for him. He tries to make this world his own, understandable, familiar, harmonious and safe for living and preserving the humane in a man. This is his spiritual fortress, in which he feels protected.

\section{NEED OF NEW ECOHUMANITARIAN APPROACH}

The surrounding world in the modern philosophic understanding is both the natural environment, the cultural and historical space, the urban environment, the virtual space, the everyday linguistic environment, and the values that dominate in relations that are part of a single ecological system and are responsible for the environmental safety of a man - the state of individual, social and national protection against the consequences of anthropo- and technogenic impact. Social space is characterized by special ways of human existence - symbolic meanings, the results of historical creativity, spirituality, which form the world outlook, dictate the patterns of social behavior, reproduce the person himself in his spiritual and moral essence. The sociocultural environment, as well as the natural-biological environment, must preserve health. And we are speaking in this case not only about person's physical health, but also about mental, cultural and moral health, without which it is impossible to reproduce civilization at a proper level, without degradation leading to the gradual degeneration of mankind.
According to the World Health Organization, urbanization processes leads to a steady increase in the number of mental illnesses. The level of morality is steadily falling, as evidenced by world political crises and degraded norms of international relations. It is time to seriously develop such concepts as "ecology of culture", "city ecology", "landscape ecology", "evolutionary ecology", "spiritual ecology", "language ecology", "ecology of ethnos", that require the involvement of not only philosophers and sociologists, but also psychologists, physiologists, doctors, culturologists, architects, artists, linguists and politicians.

A broadecophilosophic view will reveal potential opportunities and perspectives of social management on the basis of anthropological and ecological references and ecohumanitarian modeling of the future [2]. The range of ecophilosophicproblems is very broad - from an ecologically-oriented comprehension of the values and achievements of modern sciences to the creation of a new world picture, which gives the possibility of developing a new environmental culture of mankind. Even problems of the human community that seem private should be reconsidered [3; 4].

The fact that the visual environment dominating today seriously affects a person's condition is not a surprise for anyone any more. Even ancient Egyptians knew about the power and influence of color on a man and built colored halls in temples and palaces for medical and other purposes. Today,we can speak about videoecology (ecology of visual perception), arcology (ecology of architecture) in scientific terms. The urban environment over the past $50-70$ years in most countries became increasingly aggressive towards a man - the ill-considered development plans disturbed the harmony of perception (this is relevant for Moscow at the end of the 20th century); homogeneous (gray concrete walls and asphalt spaces) and "aggressive" (repeating elements, straight lines, running lines of advertising) fields make you depressed with their monotony and prevent from concentrating. With the simultaneous impact of various manmade loads in conditions of dense urban development, the state of ecosystems deteriorates sharply due to the effect of ecological resonance [5]. Overconsolidation and overcrowding affect the growth of violence and crime, drug addiction and vandalism, which create a number of sociopsychological problems, including deidentification. In the urban environment, it is also impossible to admire the sunset, shining stars or look at the horizon because of packed skyscrapers that create the atmosphere of a "bag with stones".

If the habitual cultural and aesthetic image of social space changes, and traditional national forms are replaced by standardized, unified, faceless creations, the meaning, symbolism of such a social space, its humanitarian content disappears. Along with this, a person loses his personal, private place in it (loss of sense of place and territoriality). This environment becomes alien and incomprehensible to humans. Thus, the spots with cultural and historical sites and buildings creating a harmonious sophisticated atmosphere which energizes, inspires, brings the peace of mind should be valued and protected even more ... This is an example of a health-preserving socio-cultural environment. 


\section{CUlTural ENVIRONMENT AS ECOlOGICAL FACTOR}

One of the features of a man as anancestral being is the necessity of his presence in the field of culture, without which he cannot form, preserve, manifest and continue his best human qualities. Thus, the socio-cultural environment is the same natural condition for the functioning of a man and society, as well as natural and biological environment. Culture is both frozen and living cultural monuments, bearing the genetic memory of centuries and traditions; this is the value relationship between people, the dialogue of various societies, and the inner secret world of human consciousness. This all creates a special sphere of ecological space necessary for self-realization, self-preservation of a man and harmonization of his relations with the surrounding world. Moreover, the establishment of harmony of relations with nature with the need to harmonize social and cultural relations.

Cultural heritage in the modern era becomes especially relevant, as S. Huntington wrote in the famous geopolitical treatise The Clash of Civilizations [6]. At the stage of active migration, a person often finds himself in a social and cultural environment that is uncharacteristic of him which causes him internal disharmony, conflicts and often deviant forms of behavior.This threatens the processes of deidentification, which are accompanied by the loss of cultural and spatial values and the socio-psychological disorganization of the individual. He treats space with indifference or hostility, which is often associated with manifestations of social alienation: a sense of impotence, cultural exclusion, social isolation.

Humanism as a great spiritual conquest and pillar of human development has been shaken, which leads to the degradation of the surrounding social environmentand creation of active forms of anti-culture. Even before Spengler, the Russian poet A.Blok wrote with amazing insightfulness, "The balance between a man and nature, between life and art, between science and music, between civilization and culture - the equilibrium that was the heart of the great movement of humanism - has been lost" [7].

Spiritual creative environment is not developed by itself and requires a variety of activities to create it. This is relevant today amid the crisis of spirituality, characteristic of the whole world community. Al Gore (USA) in his monograph Earth in the Balance. Ecology and the Human Spirit characterizes this tendency of spiritual and moral social and ecological space pathology: "I also came to a deeper understanding of the most frightening fact of all that we had to face in our age: civilization is capable of destroying itself ... All this is evidence of spiritual crisis of modern civilization, generated by its inner emptiness and the absence of a great spiritual goal" [8].

It is possible to overcome this situation by developing a new broader ecophilosophic view on the world and supplementing the familiar picture of the world with it. The Dutch researcher G. Salmon expressed this trend as follows: "A new science appears based on communication with living reality. Many people do not feel comfortable in the world created by modern science because it does not allow them to communicate with reality, to understand the depths of natural beings and other people. And this reality dies (which we see around us): people die internally empty, deprived of social sympathy for each other. If we want to save humanity, then we must ... create a "spiritual science" in which knowledge will be a form of love and a way of communicating with reality ... "[9]. This requires a certain socio-ecological strategy aimed at the development of a new ecological culture of a modern man. The Russian academician N.N. Moiseev introduced the concept of ecological imperative, which should become an integral part of the new thinking [10].

What features will characterize it? First, the principle of causing the least harm to socio-biological systems (including cultural ones). Secondly, the principle of preserving traditions andsocio-biological diversity, including cultural diversity, conservation. Thirdly, the principle of humanization of the environment, its spiritualization. The loss of spirituality in human relations is, first of all, the dehumanization of our environment. Fourthly, the principle of harmonization of relations with the environment and coevolution. Fifthly, the principle of the formation of ecooriented attitudes and values in the human community.

\section{CONCLUSION}

Thus, in the modern world, environmental problems are systemic, multilevel. Their solution should also be systemic, comprehensive, and it is impossible to achieve positive "ecological worldview" just with some appeals or methods of economic stimulation. It is necessary to systematically develop the values of a broad eco-humanitarian view on the world and create appropriate technology for ecophilosophic forecasting of the future. A man should feel not only being a part of the natural Cosmos, but also needs to understand his spiritual creative role, which preserves all forms of life on Earth. Such consistent activity should not only prevent the disastrous consequences of man's thoughtless behavior and his mistakes, but also improve the biological and sociocultural conditions for the development of a man and all life on Earth.

\section{REFERENCES}

[1] V. Theobald, Ecology as Ersatz-Religion and the Question of its Rational Substantiation // Issues of Philosophy. 2003, No. 12, p. 93.

[2] Barkova E., Ivleva M., Buzskaya O., Buzskij M. Ecology of culture in the space of social and humanitarian knowledge // Proceedings of the 2017 2rd International Conference on Contemporary Education, Social Sciences and Humanities 2017,pp. 12-15.

[3] Chistyakova O.V. Self and Other in the communicative space of the global world // Proceedings of the 2017 2rd International Conference on Contemporary Education, Social Sciences and Humanities 2017, pp. 6-11.

[4] Chistyakova O.V. A view on contemporaneity through the discourse of postmodernism // Proceedings of the 2017 2rd International Conference on Contemporary Education, Social Sciences and Humanities 2017, pp. 96-100.

[5] V.Telichenko, A. Bolsheotov, The Effect of Environmental Resonance in the Concentration of Construction (real estate) // Industrial and Civil Construction. 2010, No. 6,p.14. 
[6] S. Huntington, The Clash of Civilizations. Moscow: AST, 2007,pp. $15,22-23$.

[7] A. Block, The Collapse of Humanism / / A. Block. Coll. Works: In 8 vol. Vol.6. Moscow, 1962,pp.100-101.

[8] E. Horus, Earth on the Scales. Ecology and the Human Spirit / Trans. with Eng. /. Moscow: SPP, 1993, pp.12; 404.

[9] G. Salmon, Science as Power and Science as Communication (Confrontation between Two Traditions) // Philosophical Studies, 1993, No. 3, pp. 60-67.

[10] N. Moiseev, "Sustainable Development" or "Transition Strategy" // Action Plan - "Sustainable Netherlands". Moscow, 1995. 